\title{
Does the flushing response modify the relationship between alcohol intake and hypertension in the Japanese population? NIPPON DATA2010
}

\author{
Mana Kogure $^{1}$, Naho Tsuchiya ${ }^{1}$, Atsushi Hozawa ${ }^{1}$, Naoki Nakaya ${ }^{1}$, Tomohiro Nakamura ${ }^{1}$, Naomi Miyamatsu ${ }^{2}$, \\ Hideo Tanaka ${ }^{3}$, Ichiro Wakabayashi ${ }^{4}$, Aya Higashiyama ${ }^{5}$, Nagako Okuda ${ }^{6}$, Naoyuki Takashima ${ }^{7}$, \\ Akira Fujiyoshi ${ }^{7}$, Aya Kadota ${ }^{7,8}$, Takayoshi Ohkubo ${ }^{9}$, Tomonori Okamura ${ }^{10}$, Hirotsugu Ueshima ${ }^{7,8}$, \\ Akira Okayama $^{11}$ and Katsuyuki Miura ${ }^{7,8}$ for the NIPPON DATA2010 Research Group ${ }^{12}$
}

The influence of alcohol intake on hypertension may vary depending on the flushing response, but this relationship has not been confirmed. The relationship between alcohol intake and hypertension was examined according to the flushing response in a representative sample of the Japanese population. Participants in the National Health and Nutrition Survey in 2010 were asked to participate in the baseline survey of NIPPON DATA2010. Here, we investigated the relationship between alcohol intake and hypertension according to the flushing response. Statistical analyses were performed in a cross-sectional manner using multiple logistic regression models after adjusting for age, body mass index, smoking status, present illness of diabetes mellitus and present illness of dyslipidemia. Of the 1139 men and 1263 women, 659 and 463, respectively, had hypertension. Among the men, alcohol intake was positively associated with hypertension, regardless of the flushing response ( $P$ for linear trend both $<0.05)$. This positive relationship was observed for both users and non-users of antihypertensive drugs. No interaction with the flushing response was observed $(\boldsymbol{P}$ for interaction $=0.360)$. In women, although the direction differed between flushers and non-flushers, the association between alcohol intake and hypertension was not significant, regardless of flushing response. In conclusion, In Japanese men, alcohol intake was positively associated with hypertension in a manner that was not influenced by the flushing response.

Hypertension Research (2016) 39,670-679; doi:10.1038/hr.2016.46; published online 12 May 2016

Keywords: alcohol intake; flushing response; nippon DATA2010

\section{INTRODUCTION}

Heavy alcohol intake is a known risk factor of hypertension. ${ }^{1}$ After alcohol intake, some people exhibit a flushing response (palpitations, shortness of breath, headaches and/or facial flushing) because of the accumulation of acetaldehyde. Acetaldehyde, a toxic metabolite of alcohol, is oxidized in the mitochondria by aldehyde dehydrogenase $(\mathrm{ALDH}) . \mathrm{ALDH}$, the second enzyme in the metabolic pathway, converts acetaldehyde to acetic acid and consists mainly of two isozymes (ALDH1 and $\mathrm{ALDH} 2)^{2} \mathrm{ALDH} 2$ has three genotypes: wild type $\left(\operatorname{ALDH} 21 / 2^{1}\right)$, inactive heterozygote $\left(2^{1} / 2^{2}\right)$ and inactive homozygote $\left(2^{2} / 2^{2}\right)$. The ALDH2 genotype is determined by heredity;
$37-45 \%$ of Japanese individuals are inactive heterozygotes, while $7 \%$ are inactive homozygotes. ${ }^{3-5}$ People who are inactive heterozygotes or inactive homozygotes tend to exhibit a flushing response. ${ }^{3,6,7}$ A simplified flushing questionnaire has been developed to predict the ALDH2 genotype. ${ }^{8}$

Several studies have examined the relationship between alcohol intake and hypertension according to the flushing response. ${ }^{9-13}$ However, the results have conflicted. Some studies have reported that the relationship between alcohol intake and hypertension differs by flushing response. ${ }^{9,10}$ On the other hand, several reports have concluded that the ALDH2 genotype does not modify the relationship

${ }^{1}$ Division of Personalized Prevention and Epidemiology, Tohoku University Graduate School of Medicine, Sendai, Japan; ${ }^{2}$ Department of Clinical Nursing, Shiga University of Medical Science, Shiga, Japan; ${ }^{3}$ Division of Epidemiology and Prevention, Aichi Cancer Center Research Institute, Nagoya, Japan; ${ }^{4}$ Department of Environmental and Preventive Medicine, Hyogo College of Medicine, Hyogo, Japan; ${ }^{5}$ National Cerebral and Cardiovascular Center, Osaka, Japan; ${ }^{6}$ Department of Health and Nutrition, University of Human Arts and Sciences, Saitama, Japan; ${ }^{7}$ Department of Public Health, Shiga University of Medical Science, Shiga, Japan; ${ }^{8}$ Center for Epidemiologic Research in Asia, Shiga University of Medical Science, Shiga, Japan; ${ }^{9}$ Department of Hygiene and Public Health, Teikyo University School of Medicine, Tokyo, Japan; ${ }^{10}$ Department of Preventive Medicine and Public Health, School of Medicine, Keio University, Tokyo, Japan and ${ }^{11}$ Research Institute of Strategy for Prevention, Tokyo, Japan

12The members of The NIPPON DATA2010 Research Group are listed before References.

Correspondence: M Kogure, Division of Personalized Prevention and Epidemiology, Tohoku University Graduate School of Medicine, 2-1, Seiryo-machi, Aoba-ku, Sendai, Miyagi 980-8575, Japan.

E-mail: m-kogure@med.tohoku.ac.jp

Received 21 August 2015; revised 22 February 2016; accepted 20 March 2016; published online 12 May 2016 
between alcohol intake and hypertension or blood pressure (BP). ${ }^{11-13}$ However, to our knowledge, there have been no reports examining alcohol intake and lack of $\mathrm{BP}$ control according to the flushing response.

To investigate the relationship between alcohol intake and hypertension according to the flushing response in the general Japanese population, we performed a cross-sectional analysis according to sex in a representative Japanese sample, NIPPON DATA2010, consisting of subjects who participated in the National Health and Nutrition Survey of Japan.

\section{METHODS}

\section{NIPPON DATA2010}

National Integrated Project for Prospective Observation of Non-communicable Disease and Its Trends in the Aged 2010 (NIPPON DATA2010) was created as a prospective cohort to study cardiovascular disease in 2010. The baseline survey was conducted as the National Health and Nutrition Survey of Japan in 2010 (NHNS2010), which was implemented by the Ministry of Health, Labour and Welfare of Japan. The details of NHNS2010 have been described elsewhere. $^{14}$

In November 2010, a total of 8815 residents from 300 randomly selected districts throughout Japan participated in NHNS2010. Overall, 7229 of the participants were over 20 years of age. Of these participants, 3873 (men: 1598; women: 2275) completed the blood tests that were part of NHNS2010, and 2898 participants (men: 1239; women: 1659) subsequently agreed to participate in the baseline survey of NIPPON DATA2010 (response rate: 74.6\%). The age distribution was similar between NIPPON DATA2010 participants and NHNS2010 participants (Table 1). ${ }^{15}$ The baseline survey included an electrocardiography examination, blood tests, urinalysis and a questionnaire containing questions relevant to the study of cardiovascular disease. Trained researchers collected informed consent from the participants before they were enrolled.

The data from seven persons could not be utilized, and these subjects were excluded. Finally, 2891 participants (men: 1236; women: 1655) were included in the analysis. The Institutional Review Board of Shiga University of Medical Science (No. 22-29, 2010) approved this study.

\section{Study participants}

In the main analysis, we examined the relationship between alcohol intake and hypertension according to the flushing response. Of the 2891 participants, we excluded 489 for the following reasons: self-reported ex-drinkers $(n=61)$, missing information (flushing response, alcohol intake, body mass index, smoking status, present illness of diabetes mellitus, and present illness of dyslipidemia and/or antihypertensive drug use) at baseline $(n=17)$, and neverdrinkers $(n=411)$. We excluded ex-drinkers from the analysis because these individuals might have stopped drinking because of hypertension or some other chronic condition. We also excluded never-drinkers from the analysis because the questionnaire on flushing response could not be completed by individuals who had never drank. Overall, 2402 participants (men: 1139; women: 1263) were included in the analyses.

\section{Flushing response}

We set the exposure as alcohol intake depending on the flushing response. We used a simplified flushing questionnaire to evaluate the flushing response. ${ }^{8}$

The questionnaire consisted of two questions: (a) 'Do you flush in the face immediately after drinking a glass of beer?' (possible answers: partly, entire face, no or unknown) and (b) 'Did you flush in the face immediately after drinking a glass of beer during the first to second year after you started drinking?' (possible answers: yes, no or unknown).

We classified the participants into two groups according to their answers. Individuals who answered 'partly' or 'entire face' to question (a) were classified as 'flushers.' Furthermore, those who answered 'no' or 'unknown' to question (a) and 'yes' to question (b) were also classified as 'flushers.' The remaining subjects were classified as 'non-flushers.'

\section{Alcohol intake}

Information on alcohol intake (frequency and amount per day) was ascertained using a self-reported questionnaire. The frequency of alcohol intake was classified into the following six categories: every day, 5-6 days per week, 3-4 days per week, 1-2 days per week, 1-3 days per month and almost never. Alcohol intake was grouped into the following six categories: $\geqslant 5,4-5,3-4,2-3$, $1-2$ and $<1$ gou per day, where 'gou' represented the traditional Japanese unit of sake. For sake, 1 gou $(180 \mathrm{ml})$ is equivalent to $22.1 \mathrm{~g}$ of alcohol, which is roughly two single shots of whisky $(70 \mathrm{ml})$ or one bottle of beer $(633 \mathrm{ml})$. The average weekly alcohol intake (g per week) was calculated for each participant using data on the frequency and amount of alcohol intake. The average frequencies and amounts used for each category were as follows: for frequency, $7,5.5,3.5,1.5,0.5$ and 0 days per week, and for amount, 5 gou per day ( $=110.5 \mathrm{~g}$ of ethanol), 4.5 gou per day ( $=99.5 \mathrm{~g}$ of ethanol), 3.5 gou per day $(=77.4 \mathrm{~g}$ of ethanol), 2.5 gou per day $(=55.3 \mathrm{~g}$ of ethanol), 1.5 gou per day $(=33.2 \mathrm{~g}$ of ethanol) and 0.5 gou per day $(=11.1 \mathrm{~g}$ of ethanol). For men, alcohol intake was classified into the following four categories: $0 \mathrm{~g}$ per week (equivalent to 0 gou per day), $0.0-154.6 \mathrm{~g}$ per week (equivalent to $0<$ gou per day $<1$ ), $154.7-309.3 \mathrm{~g}$ per week (equivalent to $1 \leqslant$ gou per day $<2$ ) and more than $309.4 \mathrm{~g}$ per week (equivalent to $\geqslant 2$ gou per day). For women, alcohol intake was classified into the following three categories: $0 \mathrm{~g}$ per week (equivalent to 0 gou per day), $0.0-154.6 \mathrm{~g}$ per week (equivalent to $0<$ gou per day $<1$ ) and more than $154.7 \mathrm{~g}$ per week (equivalent to $\geqslant 1$ gou per day).

\section{BP measurement}

BP was measured twice by trained observers using a standard mercury sphygmomanometer on the right arm of seated participants. Hypertension was defined as a systolic BP (SBP) $\geqslant 140 \mathrm{~mm} \mathrm{Hg}$ and/or a diastolic BP (DBP) $\geqslant 90 \mathrm{~mm} \mathrm{Hg}$ and/or the use of antihypertensive drugs. ${ }^{16}$ The first measurement was obtained after the subject had rested in a sitting position for at least $5 \mathrm{~min}$. The average of the two measurements was used.

\section{Statistical analysis}

As the alcohol intake differed between the men and the women, the data were analyzed separately for men and for women throughout the analyses.

Regarding the characteristics of the subjects, we tested for trends in age, BP, proportion with obesity, smoking status and use of antihypertensive drugs. All

Table 1 Distribution of population by age and sex between NIPPON DATA2010 and Nutrition Survey of Japan in 2010 (NHNS2010)

\begin{tabular}{|c|c|c|c|c|c|}
\hline \multicolumn{3}{|l|}{ Men } & \multicolumn{3}{|c|}{ Women } \\
\hline Age (years) & NIPPON DATA2010 (\%) & NHS2010 (\%) & Age (years) & NIPPON DATA2010 (\%) & NHS2O10 (\%) \\
\hline 20-29 & 4.6 & 4.7 & 20-29 & 4.6 & 4.6 \\
\hline 30-39 & 9.0 & 10.1 & 30-39 & 14.0 & 14.2 \\
\hline 40-49 & 10.3 & 11.0 & $40-49$ & 11.0 & 13.5 \\
\hline $50-59$ & 15.6 & 16.2 & $50-59$ & 17.2 & 17.2 \\
\hline $60-69$ & 30.4 & 28.9 & $60-69$ & 26.2 & 24.9 \\
\hline $70 \leqslant$ & 30.2 & 29.1 & $70 \leqslant$ & 26.8 & 25.5 \\
\hline Total $(n)$ & 1239 & 1598 & Total $(n)$ & 1659 & 2275 \\
\hline
\end{tabular}


$P$-values for linear trends were calculated using the categories of alcohol intake. Additionally, we tested for interactions to compare the characteristics of flushers and non-flushers.

Multiple logistic regression models with hypertension as a dependent variable were applied to the main analyses. We included possible confounding factors, such as age, body mass index $\left(<18.5,18.5-24.9\right.$ and $\left.\geqslant 25.0 \mathrm{~kg} \mathrm{~m}^{-2}\right)$, smoking status (never-smoker, ex-smoker and current smoker), present illness of diabetes mellitus (yes, no) and present illness of dyslipidemia (yes, no) in the adjusted models. Additionally, we tested for linear trends in BP according to the flushing response and for interactions between alcohol intake and the flushing response. In the interaction term analysis, we included a cross-product term for alcohol intake and flushing response in the model.

To consider the influence of antihypertensive drugs, we stratified the participants into two groups: non-users $(n=1795)$ and users $(n=607)$ of antihypertensive drugs. Multiple logistic regression analysis was conducted for each group. In the analyses, the dependent variable was the lack of BP control, which was defined as an SBP of $\geqslant 140 \mathrm{~mm} \mathrm{Hg}$ or a DBP of $\geqslant 90 \mathrm{~mm} \mathrm{Hg}$. In both analyses, we included age, body mass index, smoking status, present illness of diabetes mellitus and present illness of dyslipidemia as potential confounding factors.

All $P$-values were two-sided, and $P<0.05$ was regarded as being statistically significant. All analyses were performed using SAS version 9.4 for Windows (SAS, Cary, NC, USA).

\section{RESULTS}

Table 2 shows the baseline characteristics of the participants according to alcohol intake and flushing response. Of the 1139 men and 1263 women, $583(51.2 \%)$ and 597 (47.3\%), respectively, were classified as flushers.

Among the men, BP increased with alcohol intake in both the flushers and the non-flushers. Similarly, the proportion of ex-smokers increased with alcohol intake among flushers, and the proportion of current smokers increased with alcohol intake among non-flushers. Meanwhile, the proportion of never-smokers decreased with alcohol intake among both flushers and non-flushers. Of the non-flushers, the non-drinkers were younger than the drinkers. We did not observe any interaction between the presence of flushing response and any of the variables that were examined.

Regarding women, individuals with a higher alcohol intake were more likely to be younger. Furthermore, the BP did not increase with alcohol intake among non-flushers. In both non-flushing and flushing women, the proportion of ex-smokers increased with alcohol intake. The relationships between alcohol intake and age, BP, smoking status and use of antihypertensive drugs differed according to the flushing response.

Table 3 shows the relationship between alcohol intake and hypertension according to the presence of flushing response. Of the 1139 men and 1263 women, 659 (57.9\%) and 463 (36.7\%), respectively, had hypertension. The prevalence of drinkers was $64 \%$, $90 \%, 34 \%$ and $58 \%$ among the male flushers, male non-flushers, female flushers and female non-flushers, respectively. In men, the median alcohol intake was $16.6 \mathrm{~g}$ per week (interquartile range: $0.0,182.3$ ) in flushers and $149.2 \mathrm{~g}$ per week (interquartile range: $38.7,232.1$ ) in non-flushers, respectively. On the other hand, the median alcohol intake among flushers was $0.0 \mathrm{~g}$ per week (interquartile range: $0.0,5.5$ ) and $5.5 \mathrm{~g}$ per week (interquartile range: $0.0,49.7)$ among non-flushers in women. The median alcohol intake was lower in flushers than in non-flushers regardless of sex.

Among men, alcohol intake was positively associated with hypertension in both flushers and non-flushers $(P$ for linear trend both $<0.05)$. Of the flushers, the adjusted odds ratio compared with the group with an alcohol intake of 0 gou per day was 1.10 (95\% confidence interval $(95 \% \mathrm{CI}), 0.71-1.72)$ for $0<$ gou per day
$<1,1.86$ (95\% CI, 1.07-3.23) for $1 \leqslant$ gou per day $<2$ and 1.91 (95\% CI, $0.92-3.96)$ for $2 \leqslant$ gou per day ( $P$ for linear trend $=0.016$ ). Of the non-flushers, the adjusted odds ratio compared with the group with an alcohol intake of 0 gou per day was 1.28 (95\% CI, 0.62-2.68) for $0<$ gou per day $<1,2.43(95 \%$ CI, 1.14-5.17) for $1 \leqslant$ gou per day $<2$ and 2.62 (95\% CI, 1.16-5.92) for $2 \leqslant$ gou per day ( $P$ for linear trend $=0.001)$. We observed no interaction with the flushing response $(P$ for interaction $=0.360)$. Among women, although the direction differed between flushers and non-flushers ( $P$ for interaction $=0.052$ ), the association between alcohol intake and hypertension was not significant, regardless of the presence of a flushing response ( $P$ for linear trend $>0.05$ ).

Table 4 shows the relationship between alcohol intake and hypertension according to the flushing response in participants who did not take antihypertensive drugs. In men, alcohol intake was positively associated with hypertension regardless of flushing response ( $P$ for linear trend $<0.05$ ). We observed no interaction with the flushing response $(P$ for interaction $>0.05)$. Among women, the association between alcohol intake and hypertension was not statistically significant for flushers or non-flushers ( $P$ for linear trend $>0.05$ ).

Table 5 shows the relationship between alcohol intake and lack of BP control $(\geqslant 140 / 90 \mathrm{~mm} \mathrm{Hg})$ according to the flushing response among participants taking antihypertensive drugs. In men, alcohol intake was positively associated with lack of BP control among flushers $(P$ for linear trend $=0.007)$. Although the difference was not statistically significant $(P$ for linear trend $=0.114)$, the adjusted odds ratio was higher in the $\geqslant 2$ gou per day group than in the lower alcohol intake groups. We observed no interaction with the flushing response $(P$ for interaction $=0.481)$. In women, the association between alcohol intake and a lack of BP control was not significant for flushers or non-flushers ( $P$ for linear trend $>0.05$ ).

\section{DISCUSSION}

We examined the relationship between alcohol intake and hypertension according to flushing response using NIPPON DATA2010, which provided data from a representative Japanese population. For men, alcohol intake was positively associated with hypertension in flushers and non-flushers. The flushing response did not modify the relationship between alcohol intake and hypertension.

In our study, the median alcohol intake was lower among flushers than among non-flushers regardless of sex. Flushers were likely to exhibit a flushing response. This could be explained by the fact that flushers had experienced the uncomfortable symptoms of the flushing response and were thus likely to stop or reduce their alcohol consumption.

For men, alcohol intake was positively associated with hypertension among both flushers and non-flushers. Our findings were consistent with the results of some studies. In a meta-analysis, male drinkers with a high alcohol intake ( $>50 \mathrm{~g}$ per day) had a higher risk of hypertension than non-drinkers (relative risk: 1.61, 95\% CI: 1.38-1.87). ${ }^{1}$ Ueshima et al. ${ }^{17}$ also found that moderate or heavy alcohol intake was associated with BP and the presence of hypertension among men in Japan.

Regarding the interaction between alcohol intake and hypertension according to flushing response, several reports have shown that alcohol intake is associated with BP among subjects with an inactive ALDH2 genotype or among flushers, but not among individuals with an active ALDH2 genotype or non-flushers. ${ }^{9,10,18,19}$ However, none of those studies presented a $P$ for interaction. In those reports, the following mechanisms were considered. Jung et al. ${ }^{19,20}$ hypothesized that the increased $\mathrm{BP}$ in flushers was caused by the release of 
Table 2 Study participants' baseline characteristics according to the alcohol intake and flushing response, NIPPON DATA2010

\begin{tabular}{|c|c|c|c|c|c|c|c|c|c|c|c|}
\hline & \multicolumn{4}{|c|}{ Flusher } & \multirow[b]{3}{*}{$\begin{array}{l}\text { P for linear } \\
\text { trend }\end{array}$} & \multicolumn{4}{|c|}{ Non-flusher } & \multirow[b]{3}{*}{$\begin{array}{l}\text { P for linear } \\
\text { trend }\end{array}$} & \multirow[b]{3}{*}{$\begin{array}{c}\mathrm{P} \text { for } \\
\text { interaction }\end{array}$} \\
\hline & \multicolumn{4}{|c|}{ Alcohol intake } & & \multicolumn{4}{|c|}{ Alcohol intake } & & \\
\hline & $\begin{array}{l}\text { O gou } \\
\text { per day }\end{array}$ & $\begin{array}{c}0<\text { gou } \\
\text { per day<1 }\end{array}$ & $\begin{array}{c}1 \leqslant \text { gou } \\
\text { per day<2 }\end{array}$ & $\begin{array}{l}2 \leqslant \text { gou } \\
\text { per day }\end{array}$ & & O gou per day & $\begin{array}{c}0<\text { gou } \\
\text { per day<1 }\end{array}$ & $\begin{array}{c}1 \leqslant \text { gou } \\
\text { per day<2 }\end{array}$ & $\begin{array}{l}2 \leqslant \text { gou } \\
\text { per day }\end{array}$ & & \\
\hline Number & 210 & 219 & 103 & 51 & & 58 & 222 & 176 & 100 & & \\
\hline $\begin{array}{l}\text { Age (year) } \\
(\text { mean } \pm \text { s.d.) }\end{array}$ & $60.5 \pm 17.1$ & $60.7 \pm 15.6$ & $61.3 \pm 11.8$ & $59.6 \pm 13.2$ & 0.971 & $52.3 \pm 19.8$ & $58.9 \pm 16.8$ & $60.3 \pm 14.3$ & $56.4 \pm 14.0$ & 0.303 & 0.427 \\
\hline $\begin{array}{l}\text { SBP }(m m ~ H g) \\
(\text { mean } \pm \text { s.d. })\end{array}$ & $132.6 \pm 16.7$ & $135.1 \pm 17.2$ & $141.0 \pm 18.4$ & $139.1 \pm 18.2$ & $<0.001$ & $131.7 \pm 17.3$ & $134.3 \pm 18.8$ & $138.8 \pm 15.6$ & $140.8 \pm 18.1$ & $<0.001$ & 0.775 \\
\hline $\begin{array}{l}\mathrm{DBP}(\mathrm{mm} \mathrm{Hg}) \\
\text { (mean } \pm \text { s.d.) }\end{array}$ & $79.0 \pm 9.7$ & $81.2 \pm 10.1$ & $85.8 \pm 11.5$ & $86.3 \pm 10.5$ & $<0.001$ & $79.2 \pm 10.7$ & $81.9 \pm 9.9$ & $83.9 \pm 11.1$ & $85.3 \pm 11.5$ & $<0.001$ & 0.202 \\
\hline $\begin{array}{l}\mathrm{BMI} \geqslant 25 \mathrm{~kg} \mathrm{~m}^{2} \\
(n, \%)\end{array}$ & 32.4 & 27.9 & 39.8 & 29.4 & 0.665 & 43.1 & 34.7 & 35.8 & 36.0 & 0.627 & 0.516 \\
\hline Smoking status ( $n$ & & & & & & & & & & & \\
\hline Current-smoker & 30.5 & 28.8 & 35.9 & 37.3 & 0.234 & 19.0 & 21.2 & 29.6 & 37.0 & 0.001 & 0.090 \\
\hline Ex-smoker & 37.6 & 43.8 & 48.5 & 51.0 & 0.026 & 31.0 & 45.1 & 44.9 & 41.0 & 0.513 & 0.296 \\
\hline Never-smoker & 31.9 & 27.4 & 15.5 & 11.8 & $<0.001$ & 50.0 & 33.8 & 25.6 & 22.0 & $<0.001$ & 0.925 \\
\hline Use of antihyperte & ive drugs ( $n, \%)$ & & & & & & & & & & \\
\hline Yes & 26.2 & 31.1 & 32.0 & 27.5 & 0.471 & 29.3 & 33.3 & 38.1 & 27.0 & 0.857 & 0.529 \\
\hline Present illness of & abetes mellitus ( & $(n, \%)$ & & & & & & & & & \\
\hline Yes & 16.2 & 16.0 & 18.5 & 21.6 & 0.358 & 8.6 & 21.2 & 17.6 & 18.0 & 0.606 & 0.799 \\
\hline Present illness of & slipidemia (n, \% & & & & & & & & & & \\
\hline Yes & 36.7 & 38.4 & 37.9 & 25.5 & 0.353 & 25.9 & 39.6 & 36.4 & 31.0 & 0.826 & 0.635 \\
\hline
\end{tabular}

Women $(n=1263)$

\begin{tabular}{|c|c|c|c|c|c|c|c|c|c|}
\hline & \multicolumn{3}{|c|}{ Flusher } & \multirow[b]{3}{*}{$\begin{array}{l}\text { P for linear } \\
\text { trend }\end{array}$} & \multicolumn{3}{|c|}{ Non-flusher } & \multirow[b]{3}{*}{$\begin{array}{l}\mathrm{P} \text { for linear } \\
\text { trend }\end{array}$} & \multirow[b]{3}{*}{$\begin{array}{l}\text { P for } \\
\text { interaction }\end{array}$} \\
\hline & \multicolumn{3}{|c|}{ Alcohol intake } & & \multicolumn{3}{|c|}{ Alcohol intake } & & \\
\hline & O gou per day & $0<$ gou per day $<1$ & $1 \leqslant$ gou per day & & O gou per day & $0<$ gou per day $<1$ & $1 \leqslant$ gou per day & & \\
\hline Number & 397 & 185 & 15 & & 280 & 316 & 70 & & \\
\hline Age (year) (mean \pm s.d.) & $54.9 \pm 15.4$ & $54.3 \pm 15.3$ & $50.9 \pm 12.1$ & 0.397 & $59.3 \pm 16.6$ & $52.4 \pm 16.1$ & $50.6 \pm 13.4$ & $<0.001$ & 0.005 \\
\hline $\mathrm{SBP}(\mathrm{mm} \mathrm{Hg})($ mean \pm s.d. $)$ & $126.6 \pm 18.7$ & $126.9 \pm 19.7$ & $123.4 \pm 14.7$ & 0.875 & $131.4 \pm 20.5$ & $124.9 \pm 18.7$ & $125.2 \pm 16.0$ & $<0.001$ & 0.029 \\
\hline $\mathrm{DBP}(\mathrm{mm} \mathrm{Hg})(m e a n \pm$ s.d. $)$ & $76.2 \pm 10.2$ & $77.4 \pm 11.7$ & $74.6 \pm 8.6$ & 0.467 & $77.1 \pm 11.1$ & $77.0 \pm 10.6$ & $77.0 \pm 9.5$ & 0.887 & 0.508 \\
\hline $\mathrm{BMI} \geqslant 25 \mathrm{~kg} \mathrm{~m}^{-2}$ (number, \%) & 22.7 & 22.2 & 6.7 & 0.399 & 22.9 & 20.6 & 15.7 & 0.198 & 0.902 \\
\hline \multicolumn{10}{|l|}{ Smoking status ( $n, \%)$} \\
\hline Current-smoker & 9.6 & 5.4 & 20.0 & 0.514 & 5.0 & 8.9 & 21.4 & $<0.001$ & 0.005 \\
\hline Ex-smoker & 7.8 & 12.4 & 26.7 & 0.009 & 6.8 & 10.8 & 22.9 & $<0.001$ & 0.811 \\
\hline Never-smoker & 82.6 & 82.2 & 53.3 & 0.123 & 88.2 & 80.4 & 55.7 & $<0.001$ & 0.023 \\
\hline \multicolumn{10}{|c|}{ Use of antihypertensive drugs ( $n, \%$ ) } \\
\hline Yes & 15.9 & 20.5 & 20.0 & 0.184 & 30.0 & 18.4 & 8.6 & $<0.001$ & $<0.001$ \\
\hline \multicolumn{10}{|c|}{ Present illness of diabetes mellitus ( $n, \%$ ) } \\
\hline Yes & 8.3 & 8.1 & 6.7 & 0.856 & 9.6 & 5.7 & 4.3 & 0.044 & 0.233 \\
\hline \multicolumn{10}{|c|}{ Present illness of dyslipidemia ( $n, \%)$} \\
\hline Yes & 37.3 & 38.4 & 26.7 & 0.835 & 37.5 & 32.6 & 17.1 & 0.003 & 0.087 \\
\hline
\end{tabular}

Abbreviations: BMI, body mass index; DBP, diastolic blood pressure; SBP, systolic blood pressure; s.d., standard deviation.

${ }^{a}$ Gou: A traditional Japanese unit of volume. One gou is equivalent to $22.1 \mathrm{~g}$ of ethanol. 

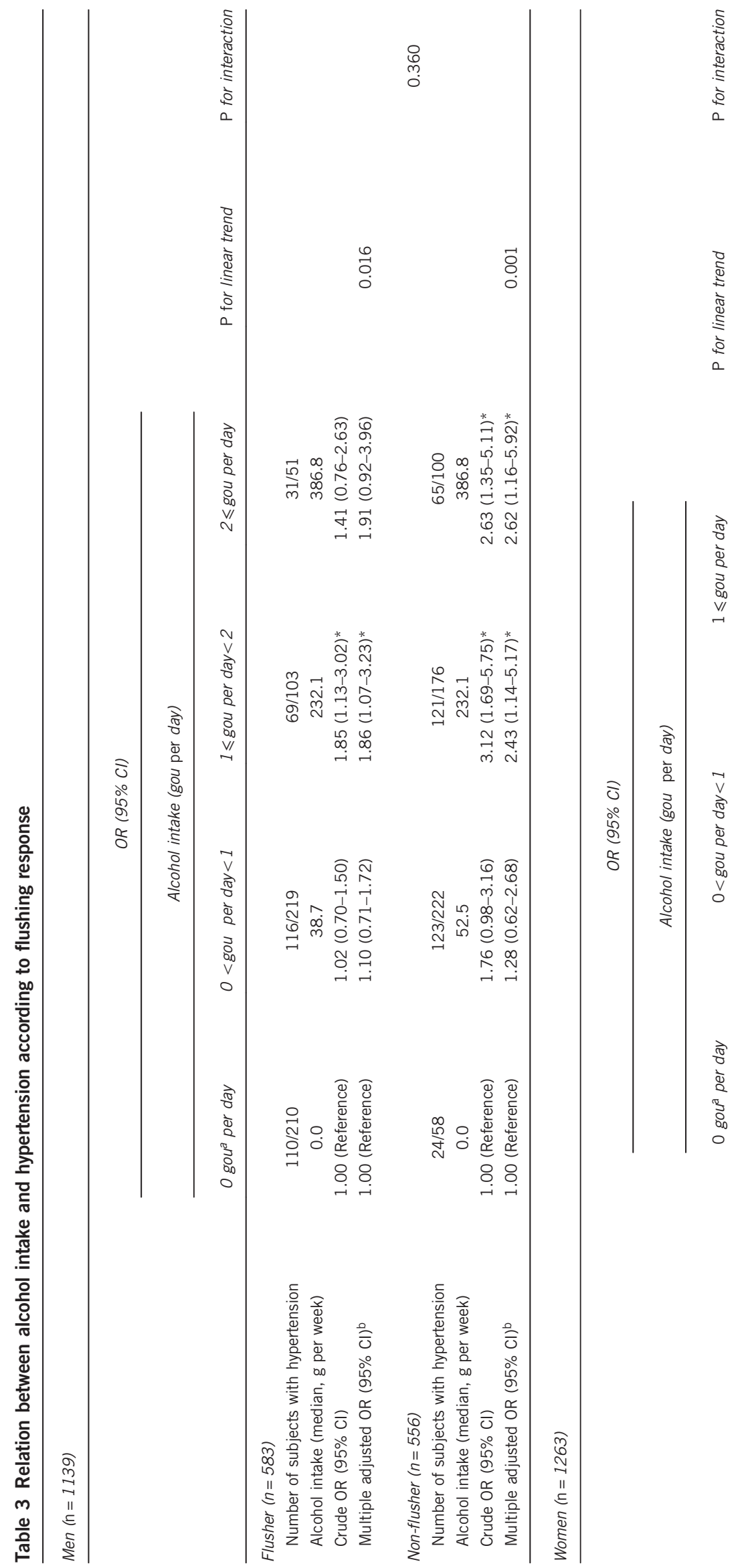

Nิ

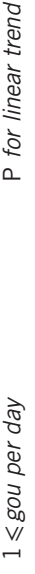

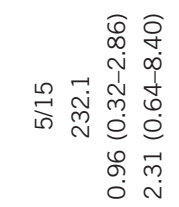

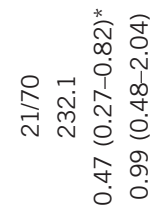

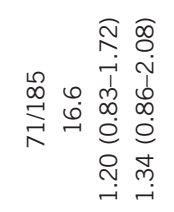

$\begin{array}{ll}* & 0 \\ 0 & 0 \\ 0 & -i \\ 0 & -i\end{array}$

$\frac{\vec{\sigma}}{8}$

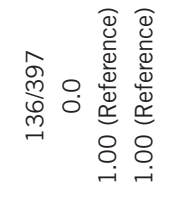

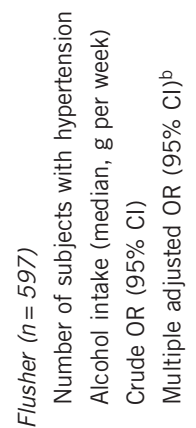




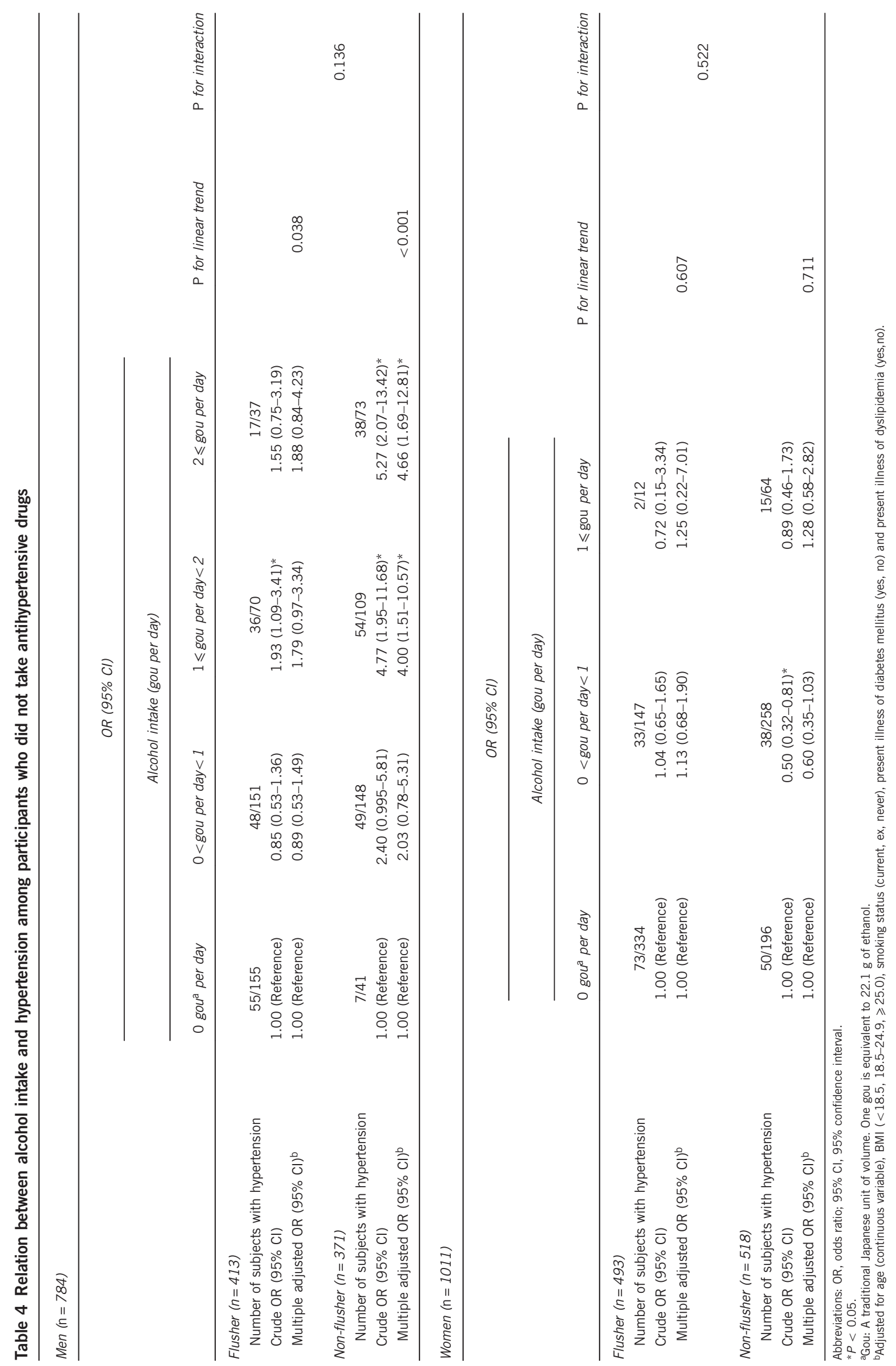

675 

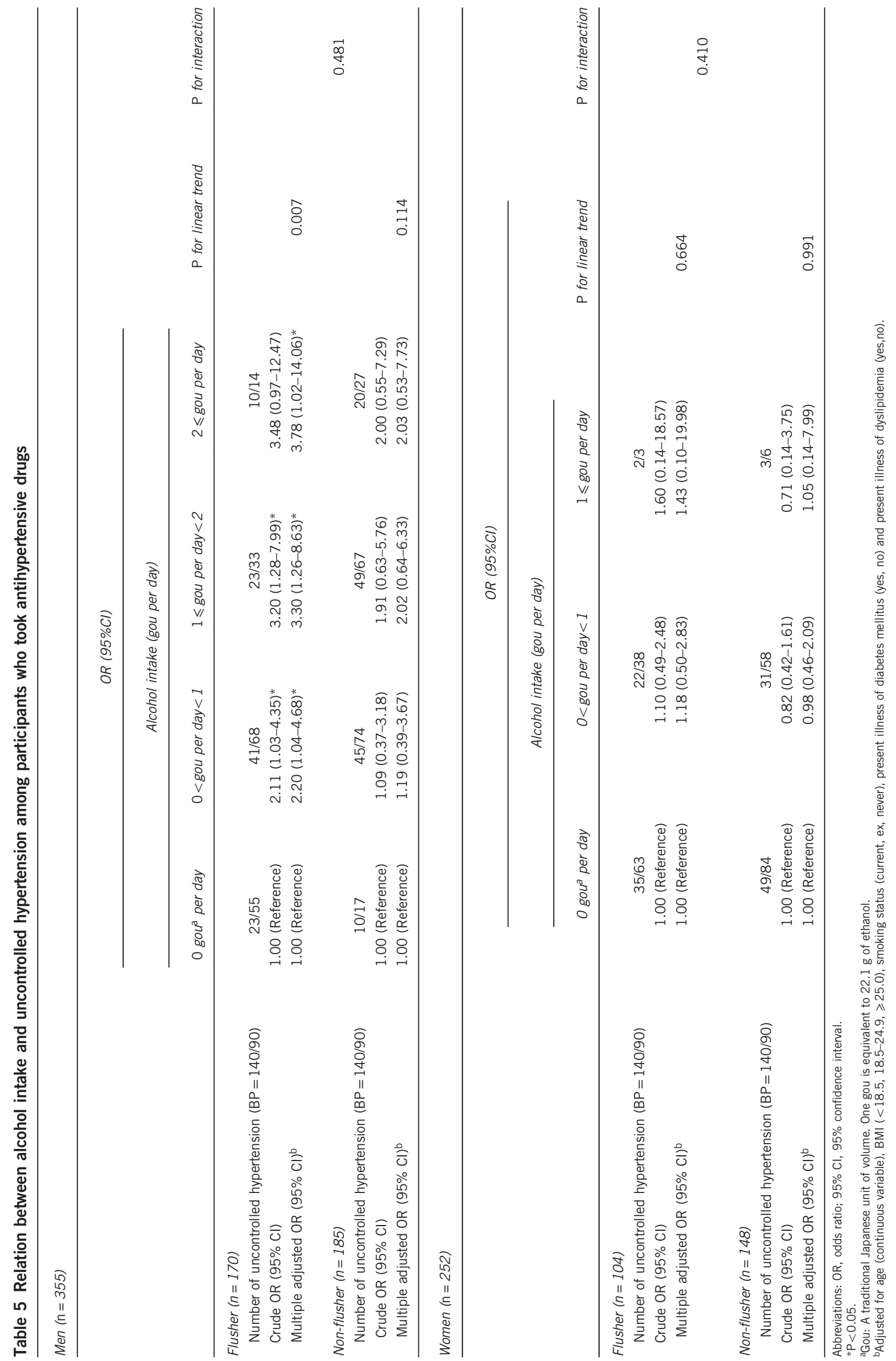
noradrenaline due to sympathetic nerve stimulation to compensate for the reduction in visceral blood flow resulting from peripheral vasodilation, which has been associated with poor acetaldehyde removal. The results of our study, however, do not support this mechanism.

We demonstrated that the flushing response did not modify the relationship between alcohol intake and hypertension among men. Our results agree with those from other studies. ${ }^{11-13,21}$ Although the results of the statistical tests examining the interaction were not provided, Amamoto et al..$^{5}$ and Okayama et al. ${ }^{22}$ also reported that the ALDH2 genotype did not modify the relationship between alcohol intake and hypertension or BP among men.

We considered several reasons for the discrepancy between our study and the previous studies mentioned above. First, the age groups differed. The mean ages were 53.3 and 39.3 years in the studies by Nakagawa et al. ${ }^{10}$ and Itoh et al., ${ }^{18}$ respectively. In the study by Jung et al. ${ }^{9}$ the mean ages were 50.9 years, 49.2 years, and 48.7 years in the non-drinkers, flushers, and non-flushers, respectively. In comparison, the mean age in our study was older (57.1 years) than those in the other studies. Second, the prevalence of hypertension differed between the studies. The prevalence of hypertension was 28 and $27 \%$ in the studies reported by Nakagawa et al. ${ }^{10}$ and Itoh et al. ${ }^{18}$ respectively. Meanwhile, in our study, the prevalence of hypertension was higher (47\%) than those of the other studies. These differences in age and prevalence of hypertension may have influenced the discrepancy between the results of our study and those of the previous studies. Another possible reason for the discrepancy may be the categorization of the ex-drinkers. None of the previous studies clearly distinguished between never-drinkers and ex-drinkers among the non-drinkers. However, we excluded ex-drinkers from the present analyses. Ex-drinkers may have stopped consuming alcohol because they were suffering from a disease. If ex-drinkers had been included among the non-drinkers, the effect of alcohol consumption on hypertension would probably have been underestimated because the prevalence of hypertension would have likely increased among the non-drinkers in our study. Thus, we believed that our approach was appropriate to assess the association between alcohol intake and hypertension.

Among women, we found no statistically significant associations between alcohol intake and hypertension, regardless of flushing response. A meta-analysis ${ }^{1}$ performed in the United States reported that the risk of hypertension was significantly higher among female drinkers (31-40 g per day) than among non-drinkers (OR: 1.19, 95\% CI: 1.07-1.32). Marmot et al. ${ }^{23}$ reported a higher BP in heavy drinkers than in non-drinkers among women. Thus, our results were inconsistent with these previous reports. Several possibilities might explain the lack of positive association between alcohol intake and hypertension in our study. First, women in Japan, especially older women, tend to not drink regardless of their flushing response. In fact, among the non-flushers, the mean age of the non-drinkers was higher. Because the mean age of the non-drinkers was higher, the BP among nondrinkers was also higher than that among those who drank $\geqslant 1$ gou per day. Although we adjusted for age, we might not have been fully able to adjust for the effects of age. Second, the number of alcohol intake categories was relatively small. Marmot et al. ${ }^{23}$ reported that among women, the mean BP was 3.9 (SBP)/3.1 (DBP) mm Hg higher in the heavy alcohol intake group $(\geqslant 34 \mathrm{~g}$ per day) than in the non-drinking group, and these differences were statistically significant. However, in our study, we could not perform a detailed categorization because the number of female drinkers was relatively small. Consequently, we were only able to define three alcohol intake groups, and this smaller number of female moderate/heavy drinkers may have also been responsible for the non-significant relationship between alcohol intake and hypertension in this study.

In this study, we analyzed antihypertensive drug users and non-users separately. For men, we observed a positive relationship between alcohol intake and hypertension regardless of the use of antihypertensive drugs. With respect to the positive association in subjects who did not take antihypertensive drugs, our finding was consistent with the results reported by Wakabayashi et al. ${ }^{24}$ They reported that among Japanese men $\geqslant 65$ years old who did not take antihypertensive drugs, the prevalence of a high SBP and a high DBP was significantly higher in excessive alcohol drinkers than in non-drinkers (OR of SBP $\geqslant 140 \mathrm{~mm} \mathrm{Hg:} 1.62$, 95\% CI: 1.18-2.23; OR of DBP $\geqslant 90 \mathrm{~mm} \mathrm{Hg:} 1.77,95 \%$ CI: $1.10-2.85$ ).

As for the positive relationship in subjects who were taking antihypertensive drugs, our finding was consistent with the results reported by Wagner et al. ${ }^{25}$ Wagner et al. ${ }^{25}$ reported that the risk of a lack of BP control was significantly higher for heavy alcohol drinkers than for non-drinkers in French men aged 35-74 years old who were being treated for hypertension (OR: 2.25, 95\% CI: 1.07-4.75). However, Wakabayashi et al. ${ }^{24}$ reported conflicting results. They did not find a significant association between excessive alcohol intake and $\mathrm{BP}$ among subjects who were taking antihypertensive drugs (OR of SBP $\geqslant 140$ mm Hg: 1.29, 95\% CI: 0.86-1.95; OR of DBP $\geqslant 90$ mm Hg: 0.93 , 95\% CI: $0.52-1.67)$. This discrepancy can be explained by the different age ranges of the participants. In our study, the participants were older than 20 years, and in the study reported by Wagner et al. ${ }^{25}$ the included subjects were aged 35-74 years; in contrast, the study reported by Wakabayashi et al. ${ }^{24}$ was limited to men over the age of 65 years.

The positive relationship between drinking and hypertension among untreated subjects suggests that some biological mechanisms may be involved. On the other hand, the positive relationship between drinking and a lack of BP control among treated subjects suggests that drug compliance might be relatively poor among heavier drinkers. Because the present study and previous studies did not measure compliance to antihypertensive drugs, future studies that account for drug compliance would be helpful in improving our understanding of the relationship between alcohol intake and BP among treated subjects.

The present study had several strengths. Our study participants were from the National Health and Nutrition Survey, which was conducted in 300 randomly selected districts across Japan in 2010. Therefore, our data were representative of current Japanese conditions. Additionally, to our knowledge, this is the first report to examine alcohol intake and a lack of BP control according to flushing response among participants taking antihypertensive drugs.

Our study also had some limitations. First, some participants may have limited their alcohol consumption because of their hypertension. These participants would have been classified in the lower alcohol categories. Accordingly, the effect of alcohol intake on hypertension may have been underestimated because of the higher estimated prevalence of hypertension in the lower alcohol intake categories. However, we found that for men, alcohol intake was positively associated with hypertension among both flushers and non-flushers in this study. Therefore, we considered the conclusion that alcohol intake was associated with hypertension to be robust. Second, as we did not directly determine the ALDH2 genotype, we could not classify the participants who had never drank as belonging to either the flusher or non-flusher group. Third, in our study, BP was measured at one occasion during the day. As alcohol intake has been positively associated with a morning surge in $\mathrm{BP},{ }^{26}$ assessing 24 -hour 
BP might have clarified a more detailed association between alcohol consumption and hypertension according to the flushing response. Further studies are required to address this topic. Fourth, on the basis of the cross-sectional design, it is difficult to confirm causality in this study. Finally, other potential confounding factors may have existed.

In conclusion, we found that alcohol intake was positively associated with hypertension among flushers and non-flushers without any interaction in Japanese men. In other words, a reduction in alcohol intake may be beneficial for BP reduction in both flushers and non-flushers.

\section{CONFLICT OF INTEREST}

The authors declare no conflict of interest.

\section{ACKNOWLEDGEMENTS}

This study was supported by Health and Labour Sciences Research Grants of the Ministry of Health, Labour and Welfare, Japan (Comprehensive Research on Life-Style Related Diseases including Cardiovascular Diseases and Diabetes Mellitus (H22-Junkankitou-Seishuu-Sitei-017, H25-Junkankitou-Seishuu-Sitei022)). We appreciate the efforts of the members of the NIPPON DATA2010 Research Group, who are listed below.

\section{THE NIPPON DATA2010 RESEARCH GROUP}

Chairpersons: Katsuyuki Miura (Director of the Center for Epidemiologic Research in Asia, Department of Public Health, Shiga University of Medical Science, Otsu, Shiga) and Akira Okayama (Research Institute of Strategy for Prevention, Tokyo). Research members: Hirotsugu Ueshima (Center for Epidemiologic Research in Asia, Shiga University of Medical Science, Otsu, Shiga), Shigeyuki Saitoh (School of Health Sciences, Sapporo Medical University, Sapporo, Hokkaido), Kiyomi Sakata (Department of Hygiene and Preventive Medicine, Iwate Medical University, Morioka, Iwate), Atsushi Hozawa (Department of Preventive Medicine and Epidemiology, Tohoku Medical Megabank Organization, Tohoku University, Sendai, Miyagi), Takehito Hayakawa (Department of Hygiene and Preventive Medicine, Fukushima Medical University, Fukushima), Hiroshi Yanagawa (Jichi Medical University, Shimotsuke, Tochigi), Yosikazu Nakamura (Department of Public Health, Jichi Medical University, Shimotsuke, Tochigi), Tomonori Okamura (Department of Preventive Medicine and Public Health, Keio University, Tokyo), Nobuo Nishi (Center for International Collaboration and Partnership, National Institute of Health and Nutrition, Tokyo), Nagako Okuda (Department of Health and Nutrition, University of Human Arts and Sciences, Saitama), Takayoshi Ohkubo (Department of Hygiene and Public Health Teikyo University School of Medicine, Tokyo), Fumiyoshi Kasagi (Institute of Radiation Epidemiology, Radiation Effects Association, Tokyo), Yoshitaka Murakami (Department of Medical Statistics, Toho University, Tokyo), Toru Izumi (Department of Cardio-Angiology Kitasato University School of Medicine, Sagamihara, Kanagawa), Yasuhiro Matsumura (Faculty of Health and Nutrition, Bunkyo University, Chigasaki, Kanagawa), Toshiyuki Ojima (Department of Community Health and Preventive Medicine, Hamamatsu University School of Medicine, Hamamatsu, Shizuoka), Shinkan Tokudome (Department of Public Health, Nagoya City University Graduate School of Medical Sciences, Aichi), Hideaki Toyoshima (Nagoya University, Nagoya, Aichi), Hideaki Nakagawa (Department of Epidemiology and Public Health, Kanazawa Medical University, Kanazawa, Ishikawa), Yoshikuni Kita (Faculty of Nursing Science, Tsuruga Nursing University, Tsuruga, Fukui), Aya Kadota (Center for Epidemiologic Research in Asia, Shiga University of Medical Science, Otsu, Shiga), Akira Fujiyoshi (Department of Public Health, Shiga University of Medical Science, Otsu, Shiga), Naomi Miyamatsu (Department of Clinical Nursing, Shiga University of Medical Science, Otsu, Shiga), Yasuyuki Nakamura (Department of Food Science and Human Nutrition, Ryukoku University, Otsu, Shiga), Katsushi Yoshita (Osaka City University Graduate School of human life science, Osaka), Yoshihiro Miyamoto (Department of Preventive Cardiology, National Cerebral and Cardiovascular Center, Suita, Osaka),
Kazunori Kodama (Radiation Effects Research Foundation, Hiroshima) and Yutaka Kiyohara (Department of Environmental Medicine, Kyushu University, Fukuoka), Kazuo Ueda (Murakami Memorial Hospital, Nakatsu, Oita).

1 Briasoulis A, Agarwal V, Messerli FH. Alcohol consumption and the risk of hypertension in men and women: a systematic review and meta-analysis. J Clin hypertens 2012; 14: 792-798.

2 Greenfield NJ, Pietruszko R. Two aldehyde dehydrogenases from human liver. Isolation via affinity chromatography and characterization of the isozymes. Biochim Biophys Acta 1977; 483: 35-45.

3 Takeshita T, Morimoto K, Mao X, Hashimoto T, Furuyama J. Characterization of the three genotypes of low $\mathrm{Km}$ aldehyde dehydrogenase in a Japanese population. Hum Genet 1994; 94: 217-223.

4 Wakai K, Hamajima N, Okada R, Naito M, Morita E, Hishida A, Kawai S, Nishio K, Yin G, Asai Y, Matsuo K, Hosono S, Ito H, Watanabe M, Kawase T, Suzuki T, Tajima K, Tanaka K, Higaki Y, Hara M, Imaizumi T, Taguchi N, Nakamura K, Nanri H, Sakamoto T, Horita M, Shinchi K, Kita Y, Turin TC, Rumana N, Matsui K, Miura K, Ueshima H, Takashima N, Nakamura Y, Suzuki S, Ando R, Hosono A, Imaeda N, Shibata K, Goto C, Hattori N, Fukatsu M, Yamada T, Tokudome S, Takezaki T, Niimura H, Hirasada K, Nakamura A, Tatebo M, Ogawa S, Tsunematsu N, Chiba S, Mikami H, Kono S, Ohnaka K, Takayanagi R, Watanabe Y, Ozaki E, Shigeta M, Kuriyama N, Yoshikawa A, Matsui D, Watanabe I, Inoue K, Ozasa K, Mitani S, Arisawa K, Uemura H, Hiyoshi M, Takami H, Yamaguchi M, Nakamoto M, Takeda H, Kubo M, Tanaka H. Profile of participants and genotype distributions of 108 polymorphisms in a cross-sectional study of associations of genotypes with lifestyle and clinical factors: a project in the Japan Multi-Institutional Collaborative Cohort (J-MICC) Study. J Epidemiol 2011; 21: 223-235.

5 Amamoto K, Okamura T, Tamaki S, Kita Y, Tsujita Y, Kadowaki T, Nakamura Y, Ueshima H. Epidemiologic study of the association of low-Km mitochondrial acetaldehyde dehydrogenase genotypes with blood pressure level and the prevalence of hypertension in a general population. Hypertens Res 2002; 25: 857-864.

6 Harada S, Agarwal DP, Goedde HW. Aldehyde dehydrogenase deficiency as cause of facial flushing reaction to alcohol in Japanese. Lancet 1981; 2: 982.

7 Mizoi Y, Ijiri I, Tatsuno Y, Kijima T, Fujiwara S, Adachi J, Hishida S. Relationship between facial flushing and blood acetaldehyde levels after alcohol intake. Pharmacol Biochem Behav 1979; 10: 303-311.

8 Yokoyama A, Muramatsu T, Ohmori T, Kumagai Y, Higuchi S, Ishii H. Reliability of a flushing questionnaire and the ethanol patch test in screening for inactive aldehyde dehydrogenase-2 and alcohol-related cancer risk. Cancer Epidemiol Biomarkers Prev 1997; 6: 1105-1107.

9 Jung JG, Kim JS, Kim YS, Oh MK, Yoon SJ. Hypertension associated with alcohol consumption based on the facial flushing reaction to drinking. Alcohol Clin Exp Res 2014; 38: 1020-1025.

10 Nakagawa T, Kajiwara A, Saruwatari J, Hamamoto A, Kaku W, Oniki K, Mihara S, Ogata Y, Nakagawa K. The combination of mitochondrial low enzyme-activity aldehyde dehydrogenase 2 allele and superoxide dismutase 2 genotypes increases the risk of hypertension in relation to alcohol consumption. Pharmacogenet Genom 2013; 23: 34-37.

11 Takagi S, Baba S, Iwai N, Fukuda M, Katsuya T, Higaki J, Mannami T, Ogata J, Goto Y, Ogihara T. The aldehyde dehydrogenase 2 gene is a risk factor for hypertension in Japanese but does not alter the sensitivity to pressor effects of alcohol: the Suita study. Hypertens Res 2001; 24: 365-370.

12 Saito K, Yokoyama T, Yoshiike N, Date C, Yamamoto A, Muramatsu M, Tanaka H. Do the ethanol metabolizing enzymes modify the relationship between alcohol consumption and blood pressure? J Hypertens 2003; 21: 1097-1105.

13 Tsuritani I, Ikai E, Date T, Suzuki Y, Ishizaki M, Yamada Y. Polymorphism in ALDH2-genotype in Japanese men and the alcohol-blood pressure relationship. Am J Hypertens 1995; 8: 1053-1059.

14 Ministry of Health, Labour and Welfare, Japan. The National Health and Nutrition Survey in Japan 2010. Tokyo: Office for Life-style Related Diseases Control, General Affairs Division, Health Service Bureau, Ministry of Health, Labour and Welfare, 2013 (in Japanese).

15 Ministry of Health, Labour and Welfare, Japan. The National Health and Nutrition Survey in Japan, 2010. http://www.mhlw.go.jp/bunya/kenkou/eiyou/dl/h22-houkoku-03. pdf (in Japanese, 2015.11.02 access).

16 James PA, Oparil S, Carter BL, Cushman WC, Dennison-Himmelfarb C, Handler J, Lackland DT, LeFevre ML, MacKenzie TD, Ogedegbe O, Smith SC Jr., Svetkey LP, Taler SJ, Townsend RR, Wright JT Jr., Narva AS, Ortiz E. 2014 evidence-based guideline for the management of high blood pressure in adults: report from the panel members appointed to the Eighth Joint National Committee (JNC 8). JAMA 2014; 311: 507-520.

17 Ueshima H, Shimamoto T, lida M, Konishi M, Tanigaki M, Doi M, Tsujioka K, Nagano E, Tsuda C, Ozawa H, Kojima S, Komachi Y. Alcohol intake and hypertension among urban and rural Japanese populations. J Chronic Dis 1984; 37: 585-592.

18 Itoh T, Matsumoto M, Nakamura M, Okada A, Shirahashi N, Hougaku H, Hashimoto H, Sakaguchi M, Handa N, Takeshita T, Morimoto K, Hori M. Effects of daily alcohol intake on the blood pressure differ depending on an individual's sensitivity to alcohol: oriental flushing as a sign to stop drinking for health reasons. J Hypertens 1997; 15: 1211-1217. 
19 Jung JG, Kim JS, Yoon SJ, Oh MK. Relationships among alcohol consumption, facial flushing response, and metabolic syndrome in healthy men. Ann Epidemiol 2012; 22 480-486.

20 Nishimura FT, Fukunaga T, Kajiura H, Umeno K, Takakura H, Ono T, Nishijo H. Effects of aldehyde dehydrogenase-2 genotype on cardiovascular and endocrine responses to alcohol in young Japanese subjects. Auton Neurosci 2002; 102: 60-70.

21 Yamada Y, Sun F, Tsuritani I, Honda R. Genetic differences in ethanol metabolizing enzymes and blood pressure in Japanese alcohol consumers. J Hum Hypertens 2002; 16: 479-486.

22 Okayama A, Ueshima H, Yamakawa M, Kita Y. Low-Km aldehyde dehydrogenase deficiency does not influence the elevation of blood pressure by alcohol. J Hum Hypertens 1994; 8: 205-208.
23 Marmot MG, Elliott P, Shipley MJ, Dyer AR, Ueshima H, Beevers DG, Stamler R, Kesteloot H, Rose G, Stamler J. Alcohol and blood pressure: the INTERSALT study. BMJ 1994; 308: 1263-1267.

24 Wakabayashi I. History of antihypertensive therapy influences the relationships of alcohol with blood pressure and pulse pressure in older men. Am J Hypertens 2010; 23: 633-638.

25 Wagner A, Sadoun A, Dallongeville J, Ferrieres J, Amouyel P, Ruidavets JB, Arveiler D. High blood pressure prevalence and control in a middle-aged French population and their associated factors: the MONA LISA study. J Hypertens 2011; 29: 43-50.

26 Ohira T, Tanigawa T, Tabata M, Imano H, Kitamura A, Kiyama M, Sato S, Okamura T, Cui R, Koike K. A, Shimamoto T, Iso H. Effects of habitual alcohol intake on ambulatory blood pressure, heart rate, and its variability among Japanese men. Hypertension 2009; 53: 13-19. 